\title{
Quantitative Analysis of the Marker Compounds in Salvia miltiorrihiza Root and Its Phytomedicinal Preparations
}

\author{
Dan Yuan, ${ }^{a}$ Ying-ni Pan, ${ }^{a}$ Wen-wei Fu, ${ }^{a}$ Toshiaki Makino, ${ }^{*}, b$ and Yoshihiro Kano ${ }^{b}$ \\ ${ }^{a}$ Department of Traditional Chinese Medicine, Shenyang Pharmaceutical University; 103 Wenhua Road, Shenyang, \\ 110016, China: and ${ }^{b}$ Department of Kampo Medicinal Science, Hokkaido College of Pharmacy; 7-1 Katsuraaka-cho, \\ Otaru 047-0264, Japan. Received December 13, 2004; accepted February 15, 2005; published online February 21, 2005
}

A HPLC method is described in order to separate and identify 4 phenolic compounds including lithospermic acid B, 3,4-dihydroxyphenyllactic acid (danshensu), rosmarinic acid, and protocatechuic aldehyde as well as 3 lipophilic ones (tanshinone $\mathrm{I}$, tanshinone $\mathrm{II}_{\mathrm{A}}$ and cryptotanshinone) from the roots of Salvia miltiorrihiza or the herbal product containing $S$. miltiorrihiza available in Chinese or Japanese market. The influence of extractive conditions, such as method, solvents and time, on the 4 phenolic marker components in $S$. miltiorrihiza is well discussed. In order to investigate the stability of lithospermic acid $B$, the preparation samples of an injection and a granule were analyzed after being stored at $4^{\circ} \mathrm{C}, 20^{\circ} \mathrm{C}$ and $40^{\circ} \mathrm{C}$ for up to six months.

Key words lithospermic acid B; 3,4-dihydroxyphenyllactic acid; tanshinone; Salvia miltiorrhiza; herbal medicine; stability

The roots of Salvia miltiorrhiza Bunge (Salvia Root, 丹参) are used for the preparation of phytomedicines that have been proved to be effective in the prevention and therapy for the cardiovascular diseases such as myocardial and cerebral infarction, angina pectoris, coronary heart disease, hypertensive disease, etc., ${ }^{1-3)}$ because of its multiple actions of improving blood circulation, ${ }^{4}$ attenuating changes in contraction and intracellular calcium in cardiomyocytes, ${ }^{5)}$ reducing the area of cerebral infarct, $\left.{ }^{6}\right)$ inhibiting the renin angiotensin system, ${ }^{7)}$ elevating antioxidant defense enzymes, ${ }^{8)}$ scavenging free radicals and protecting for myocardial mitochondrial membrane, ${ }^{9)}$ and so on. Two kinds of constituents useful as phytochemical markers have been identified in Salvia Root, and its preparations. ${ }^{10-12)}$ Among them, lithospermic acid B (LAB, 1), 3,4-dihydroxyphenyllactic acid (danshensu, DSS, 2), rosmarinic acid (RA, 2) and protocatechuic aldehyde (PA, 4) are the major hydrophilic constituents, derived from phenolic metabolism, while tanshinone $\mathrm{I}(\mathrm{TaI}, \mathbf{5})$, tanshinone $\mathrm{II}_{\mathrm{A}}$ $\left(\mathrm{TaII}_{\mathrm{A}}, 6\right)$ and cryptotanshinone $(\mathrm{CT}, 7)$ are the major lipophilic constituents, structurally belonging to diterpene quinone. Pharmacological studies have indicated that both hydrophilic phenolics and lipophilic quinones share many beneficial activities of Salvia Root on cardiovascular and cerebrovascular system. ${ }^{13-15)}$ For example, LAB has been found to have strong peroxynitrite scavenging activity, ${ }^{16)}$ to inhibit angiotensin converting enzyme and angiotensin I-induced contraction, ${ }^{17)}$ and to enhance angiogenesis in endothelial cell. ${ }^{18,19)}$ Unexpectedly, it has extremely low bioavailability. ${ }^{20)}$ The anticoagulative action may be predominant and characteristic among the cardiovascular effects of DSS. ${ }^{21)}$ The activity of RA on cardiovascular system should be antioxidant mechanisms due to its polyphenolic caffeic acid oligomer. ${ }^{22)} \mathrm{PA}$ also participated in the actions of Salvia Root on myocytes. ${ }^{23)}$ However, the knowledge of the cardiovascular activities of Salvia Root had begun with tanshinones and focused on for a long time, ${ }^{24-26)}$ which resulted in that $\mathrm{TaII}_{\mathrm{A}}$ had been used as the chemical marker for standardization of the crude drug and its phytomedicines.

Although phytomedicines containing Salvia Root have become, in recent years, the best selling herbal medicines for cardiovascular diseases in China, and some of them have been used as OTC in Japan, its standardization has been unclear or confused yet. In Chinese Pharmacopoeia, TaIIA has been used as a marker constituent for the quality control of this crude drug, while phenolic constituents, such as LAB and DSS, have not been respected. ${ }^{27)}$ Concerning the quality control of phytomedicines containing Salvia Root, one of the three markers, TaII $_{\mathrm{A}}$, DSS, and PA has been used. ${ }^{28-30)}$ In fact, the water extract of Salvia Root, which is the most commonly prepared for its phytomedicines, contains phenolic constituents and tanshinones should be trace in them. According to the recent study, it is worth to note that $\mathrm{TaII}_{\mathrm{A}}$ may have a potentially hazardous effect on the morphology of myocardial $^{31)}$ and the selective inhibition of murine and human CYP1A2. ${ }^{32)}$ Such confusions on the standardization should be ascribed to the lack of systematically chemical investigation on the crude drug and its phytomedicines, as well as to the lag of the standardization behind the advance on its pharmacological studies.

Several HPLC methods have been described for the analysis of the hydrophilic or lipophilic constituents of Salvia Root. $^{33-37)}$ These earlier studies were only focused on the part of these chemical markers, and were especially negligent of the stability of the polyphenolic caffeic acid polymers, such as LAB, RA, etc., during the extraction, which resulted in a great error of determined value.

In the present study, we investigated HPLC methods with photodiode array detection for the simultaneous determination of hydrophilic constituents, including LAB, DSS, RA and PA, and lipophilic constituents, including TaI, $\mathrm{TaII}_{\mathrm{A}}$ and CT (Fig. 1). And a reliable extractive procedure was also provided on the basis of the significant influence of extractive conditions, such as method, solvent, time, on the 4 phenolic marker constituents. Using both procedures, we analyzed 30 samples of Salvia Root from different cultivated farms and markets, and 21 phytomedicines from 10 manufacturers, including injections, dripping pills, capsules, granules and tablets. We also studied the stability of the phenolic constituents in the preparations of an injection and a granule in different thermal conditions. 

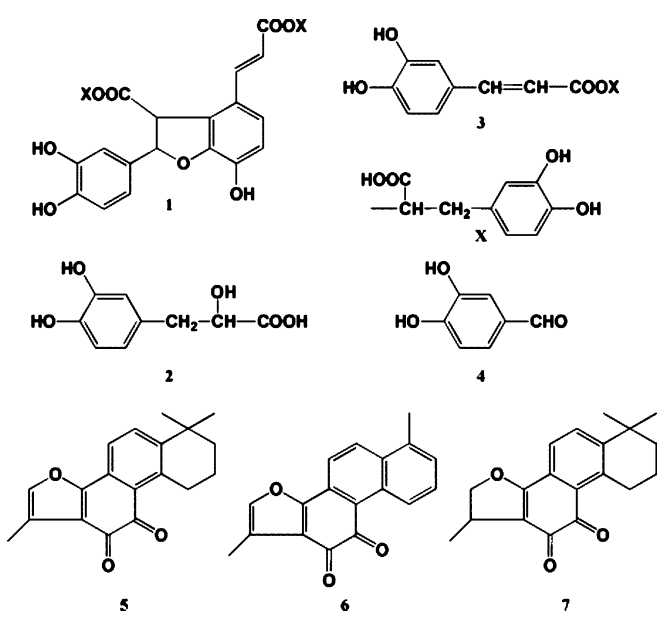

Fig. 1. Chemical Structures of Lithospermic Acid B (1), Danshensu (2), Rosmarinic Acid (3), Protocatechuic Aldehyde (4), Tanshinone $\mathrm{II}_{\mathrm{A}}$ (5), Tanshinone I (6) and Cryptotanshinone (7)

\section{Experimental}

Reference Standards LAB and RA were generously provided from Iskra Industry Co. Ltd. (Tokyo), and DSS, PA, TaI, TaII ${ }_{\mathrm{A}}$ and CT were purchased from National Institute for the Control of Pharmaceutical and Biological Products (Beijing, China). The identity of these compounds were confirmed by melting point, IR, ${ }^{1} \mathrm{H}$ - and ${ }^{13} \mathrm{C}-\mathrm{NMR}$ and $\mathrm{MS}$, and their purity evaluated with HPLC-UV was 97.1, 98.9, 99.2, 99.8, 99.3, 99.8 and 97.9\%, respectively.

Plant Materials Twenty-one samples (Sample No. 1-21), all of which were identified as roots of $S$. miltiorrhiza by authorities, were obtained directly from 6 cultivated farms, some of which have been established by Good Agricultural Practice (GAP) Regulations for crude drug, and 9 samples (Sample No. 22-30) were obtained from several Chinese markets (Table 1). All samples are kept in the reference library for the medicinal herbs in Shenyang Pharmaceutical University. For the preparation for the hydrophilic extract, the ground plant materials $(0.5 \mathrm{~g}$ : passing through $500 \mu \mathrm{m}$ mesh sieve) were extracted twice with $50 \mathrm{ml}$ of $\mathrm{MeOH}-\mathrm{H}_{2} \mathrm{O}(75: 25)$ for $15 \mathrm{~min}$ of sonication, and then centrifuged at $3500 \mathrm{rpm}$ for $10 \mathrm{~min}$. The supernatant was taken, and then the residue was refluxed with $50 \mathrm{ml}$ of $\mathrm{H}_{2} \mathrm{O}$ for $1 \mathrm{~h}$. The mixture of $\mathrm{MeOH}$ and water extracts was evaporated to dryness in vacuo. The residues were dissolved in $10 \mathrm{ml}$ of $\mathrm{H}_{2} \mathrm{O}$, and then filtered through a $0.45 \mu \mathrm{m}$ membrane filter for the analysis of 4 phenolic marker constituents. For the preparation for the lipophilic extract, the ground plant materials $(0.5 \mathrm{~g})$ were extracted with $50 \mathrm{ml}$ of $\mathrm{CH}_{2} \mathrm{Cl}_{2}-\mathrm{MeOH}(80: 20)$ for $20 \mathrm{~min}$ of sonication, and then centrifuged at $3500 \mathrm{rpm}$ for $10 \mathrm{~min}$. The supernatant was evaporated to dryness in vacuo. The residue was dissolved in $25 \mathrm{ml}$ of $\mathrm{MeOH}$, and filtered through a $0.45 \mu \mathrm{m}$ membrane filter for the analysis of 3 lipophilic marker constituents.

Commercial Preparations Several phytomedicines containing Salvia Root, such as injections, dripping pills, capsules, granules and tablets, which are available in Chinese or Japanese markets, were subjected to the analysis. Injections were directly diluted with $\mathrm{MeOH}$ at the ratio of $1: 5$, and filtered through a $0.45 \mu \mathrm{m}$ membrane filter for the analysis of 7 marker constituents. The solid preparations $(0.25-0.5 \mathrm{~g})$ were extracted with $20.0 \mathrm{ml}$ of $\mathrm{MeOH}-\mathrm{H}_{2} \mathrm{O}(75: 25)$ or with $20.0 \mathrm{ml}$ of $\mathrm{CH}_{2} \mathrm{Cl}_{2}-\mathrm{MeOH}(80: 20)$ for $15 \mathrm{~min}$ of sonication, respective for the analysis of the hydrophilic or lipophilic marker constituents. After centrifugation, the supernatants were filtered through a $0.45 \mu \mathrm{m}$ membrane filter.

Stability Test Salvia Root was dipped with $\mathrm{H}_{2} \mathrm{O}$ at $80^{\circ} \mathrm{C}$ for $2 \mathrm{~h}$, and the filtered solution was lyophilized. The water extract of Salvia Root $\left(7.465 \mathrm{mg} / \mathrm{ml}\right.$ in $\left.\mathrm{H}_{2} \mathrm{O}\right)$ or LAB solution $\left(0.345 \mathrm{mg} / \mathrm{ml}\right.$ in $\left.\mathrm{H}_{2} \mathrm{O}\right)$ were heated at $100{ }^{\circ} \mathrm{C}$, and the sample solutions were collected successively $(0.5-6 \mathrm{~h})$. In another test, the preparation samples of a granule $\left(\mathrm{K}_{\mathrm{J}}, \mathrm{EX}-252330\right)$ and an injection $\left(\mathrm{X}_{\mathrm{C}}, 030409\right)$ were stored at $4{ }^{\circ} \mathrm{C}$, at $20^{\circ} \mathrm{C}$ and at $40^{\circ} \mathrm{C}$ for six months, respectively. Samples were taken almost every month during the trial, and subsequently subjected to HPLC analysis. The control data described as month 0 was obtained from the samples just before the stability trial.

HPLC Conditions Waters HPLC system (Waters Co., Milford, MA, U.S.A.) consisting of model 717 plus autosampler, model 510 pump, auto- mated gradient controller, model 2996 photodiode array detector, and Millennium $^{32)}$ PDA software was used. HPLC analyses were carried out at $35^{\circ} \mathrm{C}$ on a Hypersil $\mathrm{C}_{18}$ column $(4.6 \times 250 \mathrm{~mm}, 5 \mu \mathrm{m}$, Thermo Electron Co, MA, U.S.A.). The detector wavelengths were $280 \mathrm{~nm}$ for 4 phenolic compounds and $254 \mathrm{~nm}$ for 3 lipophilic compounds. The injection volume was $20 \mu \mathrm{l}$. The mobile phase for the hydrophilic compounds consisted of a gradient system of solution $\mathrm{A}, \mathrm{H}_{2} \mathrm{O}$-dimethyl formamide- $\mathrm{AcOH}(94: 4: 2)$, and solution $\mathrm{B}, \mathrm{MeOH}$-dimethyl formamide- $\mathrm{AcOH}(94: 4: 2)$ at a flow rate of $1.0 \mathrm{ml} / \mathrm{min}$. The gradient program were as following: isocratic at solution A-B $(95: 5)$ for $8 \mathrm{~min}$, linear gradient to solution A-B $(75: 25)$ in $5 \mathrm{~min}$, isocratic at solution $\mathrm{A}-\mathrm{B}(75: 25)$ for $12 \mathrm{~min}$, followed by linear gradient to solution A-B $(68: 32)$ in $10 \mathrm{~min}$, finally isocratic at solution A-B $(68: 32)$ for $5 \mathrm{~min}$. For the lipophilic compounds, an isocratic system of $\mathrm{H}_{2} \mathrm{O}-\mathrm{MeOH}$ $(13: 87)$ was used. For 7 reference standards, linear calibration curves were obtained as followings: $Y=1.15 \times 10^{7} X-1.03 \times 10^{6}$ for LAB in the concentration of $0.20-3.0 \mathrm{mg} / \mathrm{ml}, Y=5.83 \times 10^{6} X-1.46 \times 10^{4}$ for DSS in 0.0040 $0.17 \mathrm{mg} / \mathrm{ml}, Y=1.46 \times 10^{7} X-7.39 \times 10^{4}$ for RA in $0.0080-0.30 \mathrm{mg} / \mathrm{ml}, Y=$ $4.91 \times 10^{7} X-2.10 \times 10^{4}$ for PA in $0.0010-0.040 \mathrm{mg} / \mathrm{ml}, Y=1.68 \times 10^{8} X-$ $4.64 \times 10^{4}$ for TaI in $0.00060-0.030 \mathrm{mg} / \mathrm{ml}$, and $Y=9.90 \times 10^{7} X-1.05 \times 10^{5}$ and $Y=9.32 \times 10^{7} X-8.96 \times 10^{4}$ respectively for TaIIa and CT in 0.0020 $0.10 \mathrm{mg} / \mathrm{ml}$.

\section{Results and Discussion}

HPLC Analysis Figure 2 shows two characteristic HPLC profiles of all the reference compounds tested, i.e., four phenolic derivatives, LAB, DSS, RA, and PA, and three diterpene quinones, $\mathrm{TaI}, \mathrm{TaII}_{\mathrm{A}}$ and $\mathrm{CT}$. As can be seen, all the compounds are satisfactory separated. The UV spectra of 7 marker compounds were given by photodiode array detection, in which the UV maxima were found: $287 \mathrm{~nm}$ for LAB, $330 \mathrm{~nm}$ for RA, $280-281 \mathrm{~nm}$ for DSS and PA, $269 \mathrm{~nm}$ for $\mathrm{TaII}_{\mathrm{A}}, 244 \mathrm{~nm}$ for TaI, and $263 \mathrm{~nm}$ for CT. The detective wavelength settings were at $280 \mathrm{~nm}$ for the hydrophilic compounds and $254 \mathrm{~nm}$ for 3 tanshinones by comparison of HPLC chromatograms of sample solutions at different wavelengths.

The detection limits of the different components were $c a$. $0.68-8.11 \mathrm{ng}$. The relative standard deviation found for 10 analyses was from $0.3 \%$ to $0.7 \%$ for 7 markers. Compared with earlier work ${ }^{35)}$ the sensitivity and reproducibility were markedly improved. This analytical procedure is suitable for standardization of Salvia Root as well as its extract and phytomedicines based on their characteristic compounds.

Extraction of Marker Components from Salvia Root In order to optimize the extraction of the various secondary phenolic metabolites from crude plant material, we compared several solvents and extraction procedures. For LAB and RA, ultrasonic extraction with $\mathrm{MeOH}-\mathrm{H}_{2} \mathrm{O}(75: 25)$ for $15 \mathrm{~min}$ resulted in exhaustion of raw plant material. In contrast, such extraction did not yield a complete extraction of DSS and PA in that period. The combination of an ultrasonic extraction $(15 \mathrm{~min})$ with $\mathrm{MeOH}-\mathrm{H}_{2} \mathrm{O}(75: 25)$ and following via Soxhlet extraction $(1 \mathrm{~h})$ with $\mathrm{H}_{2} \mathrm{O}$ is, therefore, preferred to the phenolic constituents. For the tanshinones, an ultrasonic extraction $(20 \mathrm{~min})$ with $\mathrm{CH}_{2} \mathrm{Cl}_{2}-\mathrm{MeOH}(80: 20)$ is needed.

The cultivation and selection of Salvia Root should be based on the amount of tanshinones and phenolic constituents. As shown in Table 1, we found that the species contained only low levels of DSS $(0.03-0.2 \%)$, RA ( 0.04 $0.66 \%)$ and PA $(0.00-0.02 \%)$, but high levels of LAB $(0.6-7.7 \%)$. The findings mean that LAB is a predominant phenolic derivative in the crude drug material. The data are not in agreement to those in some previous literatures, ${ }^{35,37)}$ which is attributed to the differences in extraction proce- 

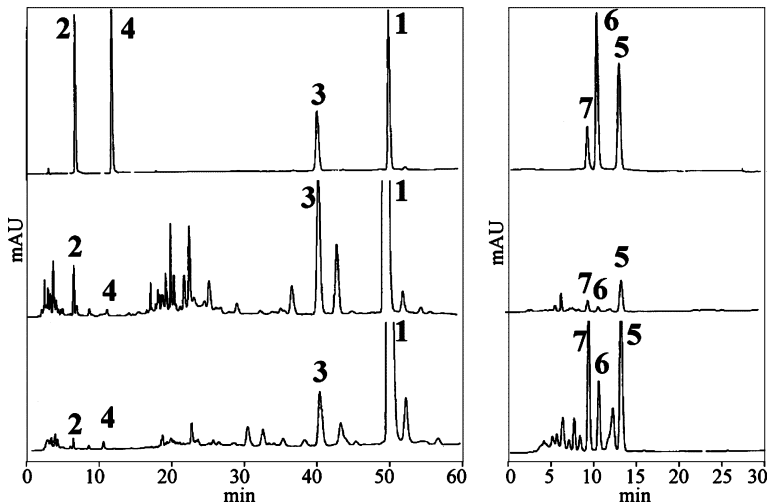

Fig. 2. HPLC Chromatograms of Standard Solutions as Well as the Extracts of Salvia Root

The uppers indicate two standard solutions, the left containing lithospermic acid B (1), danshensu (2), rosmarinic acid (3) and protocatechuic aldehyde (4), the right containing tanshinone I (5), tanshinone $\mathrm{II}_{\mathrm{A}}(\mathbf{6})$ and cryptotanshinone (7). The middle and the lower indicate two samples of Salvia Root from Sichuan and Shandong, respectively. For HPLC conditions, see Experimental section.

dures. According to our experiments, a direct Soxhlet extraction with $\mathrm{H}_{2} \mathrm{O}$ for a long period (over $1 \mathrm{~h}$ ) could result in the decomposition of LAB and RA and the formation of DSS, as shown in Table 2. Moreover, we investigated the stability of $\mathrm{LAB}$ in water solution by heating process to confirm this result. The decomposition of LAB was seen similar to the extract of Salvia Root, although the reaction was not quantitative and DSS was not the only product (Fig. 3). The heating process with water as solvent is commonly employed in the extraction for not only chemical analysis but also a production of Salvia Root extract and phytomedicines. It is speculated that the DSS content must be much higher level in the heated extract than the actual value, just like the results in earlier literatures. ${ }^{35,37)}$ In the view of the risk from the decomposition of phenolic caffeic acid polymer such as LAB, a pre-extraction like what we employed in this study is, thus, reliable in an analytical procedure or a validated method.

The contents of tanshinones (Table 1) varied from $0.056 \%$ to $0.558 \%$ for $\mathrm{TaII}_{\mathrm{A}}$, from $0.006 \%$ to $0.107 \%$ for TaI, from $0.016 \%$ to $0.38 \%$ for CT. However, the average content of $\mathrm{TaII}_{\mathrm{A}}$ in 30 samples were only $0.18 \pm 0.12 \%$, and about $66 \%$ out of 30 samples is not suitable for the standardization of $\mathrm{TaII}_{\mathrm{A}}$, being more than $0.2 \%$ listed in the Chinese Pharmacopoeia. The limit standard of $\mathrm{TaII}_{\mathrm{A}}$ for the crude plant materials should be, thus, revised in the near future, in response to the potentially hazardous effect of $\mathrm{TaII}_{\mathrm{A}}$ on morphology of myocardial $^{31)}$ and our current analytical evidence.

Analysis of Phytomedicines Containing Salvia Root The analytical procedures described above were also applied to some phytomedicines containing Salvia Root available on Chinese or Japanese market. They included the preparations of injection, dripping pill, capsule, granule and tablet containing one or more other plant extracts. Apart from the variation in crude drugs used to prepare the phytomedicines, the obvious discrepancies were found with respect to the standardization and to the recommended dosage. Among them, only dripping pills and injections were standardized with respect to DSS or PA, while most capsules, granules and tablets were often not standardized even if the amount of the extract was declared.
All preparations were analyzed for their contents of the phenolics and tanshinones, and the results are listed in Table 3 with some of HPLC chromatograms shown in Fig. 4. As to five injections prepared by the same formula, remarkable differences were found in the amount of the 4 phenolic constituents, varying per day from $6.9 \mathrm{mg}$ to $17.1 \mathrm{mg}$ for LAB, from $21.2 \mathrm{mg}$ to $64.5 \mathrm{mg}$ for DSS, from $4.2 \mathrm{mg}$ to $10.2 \mathrm{mg}$ for RA, and from $4.6 \mathrm{mg}$ to $11.1 \mathrm{mg}$ for PA in spite of no clear detection of tanshinones in all of them. This data is similar to previous studies on the analysis of the Salvia Root phytomedicines. ${ }^{12)}$ This means that DSS is, in the injection preparations, a predominant constituent over LAB in view of content, which is a reversal of the composition of the phenolic constituents in the crude root materials. Such additional alteration of active constituents may be owing to the manufacturing process according to our study, as shown in Table 2.

Among the solid preparations, such differences were also found. For example, $\mathrm{K}$ series of the preparations as shown in Table 3 from $\mathrm{K}_{\mathrm{I}}$ to $\mathrm{K}_{\mathrm{L}}$ commercially available on Japanese OTC market, are granules or tablets manufactured with the same formula comprised by Salvia Root (丹参), Safflower (紅 花), Peony Root (药薬), and other three crude drugs. Despite the same formula, the 4 phenolic constituents varied per day from $38.8 \mathrm{mg}$ to $123 \mathrm{mg}$ for $\mathrm{LAB}$, from $10.0 \mathrm{mg}$ to $16.4 \mathrm{mg}$ for DSS, from $1.6 \mathrm{mg}$ to $7.0 \mathrm{mg}$ for RA, and from $0.7 \mathrm{mg}$ to $1.4 \mathrm{mg}$ for PA in 3 commercial preparations. Such composition profile of LAB and DSS in the granule is close to that in the crude material of Salvia Root. Our test further showed that $\mathrm{TaII}_{\mathrm{A}}$ was detected in 6 out of 16 solid preparations in a relative low amount.

Although $\mathrm{TaII}_{\mathrm{A}}$ has been used as an active marker for quality control, recent studies suggest that it may be a potentially hazardous constituent, as mentioned above. Thus, the standardization of the crude drug as well as the therapeutic phytomedicines needs urgently to be revised from the standpoint of toxicity or safety and product consistency.

According to some literature, the quality of phytomedicines containing Salvia Root may be related mainly to the presence of tanshinones and phenolic caffeic acid derivatives. The efficacy of these Salvia Root phytomedicines should be ascribed mainly to the multiple cardiovascular actions of phenolic caffeic acid derivatives since none or trace of tanshinone was detected in the injections or in the solid preparations. It is worth noticing that, from our analytical results, DSS content was predominant over that of LAB in the injection preparations, while an opposite composition profiles were found in the granule. Because LAB has an extremely low bioavailability in oral route, with DSS having a relative good bioavailability, such composition profiles of LAB and DSS of two preparations in different dosage forms are contradictory to the bioavailability of both components. ${ }^{20,38)}$ The standardization of these therapeutic phytomedicines will be, in this way, rather different and further comparative tests of both components on the cardiovascular pharmacology will be need.

Stability of Phytomedicines Containing Salvia Root In order to study the stability the phenolic constituents in Salvia Root preparations and to gain an insight into the variation in the amount of LAB and DSS, the samples of an injection and a granule prepared from Salvia Root and some other 


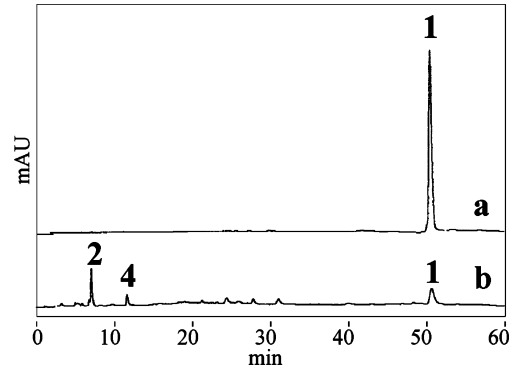

Fig. 3. HPLC Chromatograms of Freshly Prepared Lithospermic Acid B Solution (a) and the Solution after Being Heated for $6 \mathrm{~h}$ (b)

The tested water solution of lithospermic acid $\mathrm{B}$ is at the concentration of $0.34 \mathrm{mg} / \mathrm{ml}$. The others are the same as indicated Fig. 2 .

Table 2. Decomposition of LAB in Water Solution of Salvia Root Extract and Single Standard at $100^{\circ} \mathrm{C}$

\begin{tabular}{cccccc}
\hline \hline \multirow{2}{*}{ Samples } & \multirow{2}{*}{$\begin{array}{c}\text { Heating } \\
\text { time }(\mathrm{h})\end{array}$} & \multicolumn{5}{c}{ Content $(\mathrm{mg} / \mathrm{ml})$} \\
\cline { 3 - 6 } & & LAB & DSS & RA & PA \\
\hline \multirow{2}{*}{ Salvia Root extract } & 0 & 0.479 & 0.021 & 0.020 & 0.001 \\
& 0.5 & 0.459 & 0.022 & 0.019 & 0.002 \\
& 1 & 0.413 & 0.030 & 0.020 & 0.003 \\
& 2 & 0.364 & 0.050 & 0.020 & 0.007 \\
& 4 & 0.291 & 0.075 & 0.016 & 0.012 \\
& 6 & 0.238 & 0.096 & 0.010 & 0.015 \\
\cline { 2 - 2 } standard & 0 & 0.345 & n.d. & n.d. & n.d. \\
& 0.5 & 0.211 & 0.006 & n.d. & n.d. \\
& 1 & 0.142 & 0.009 & n.d. & trace \\
& 2 & 0.048 & 0.013 & n.d. & trace \\
& 4 & 0.033 & 0.020 & n.d. & 0.001 \\
& 6 & 0.032 & 0.030 & n.d. & 0.002 \\
\hline
\end{tabular}

n.d., not detectable. crude drugs were stored at $4{ }^{\circ} \mathrm{C}, 20^{\circ} \mathrm{C}$ and $40{ }^{\circ} \mathrm{C}$, and subsequently analyzed. The representative HPLC chromatograms of the stability trials were shown in Fig. 5. As shown in Fig. 6 , only less than $10 \%$ of the original level of LAB was detected in the injection after a storage period of 6 months at $40{ }^{\circ} \mathrm{C}$. After the same storage period at $4{ }^{\circ} \mathrm{C}$ or $20^{\circ} \mathrm{C}$, about $81 \%$ or $65 \%$ of the original level of LAB was still present. The granule stored at $4{ }^{\circ} \mathrm{C}, 20^{\circ} \mathrm{C}$ and $40^{\circ} \mathrm{C}$ still contained $90 \%, 81 \%$ and $67 \%$ of the original level of LAB after 6 months. With the rapid decomposition of LAB at a higher temperature of $40{ }^{\circ} \mathrm{C}$, the increase of DSS from $24 \%$ (the injection) to $37 \%$ (the granule) could be detected at the same

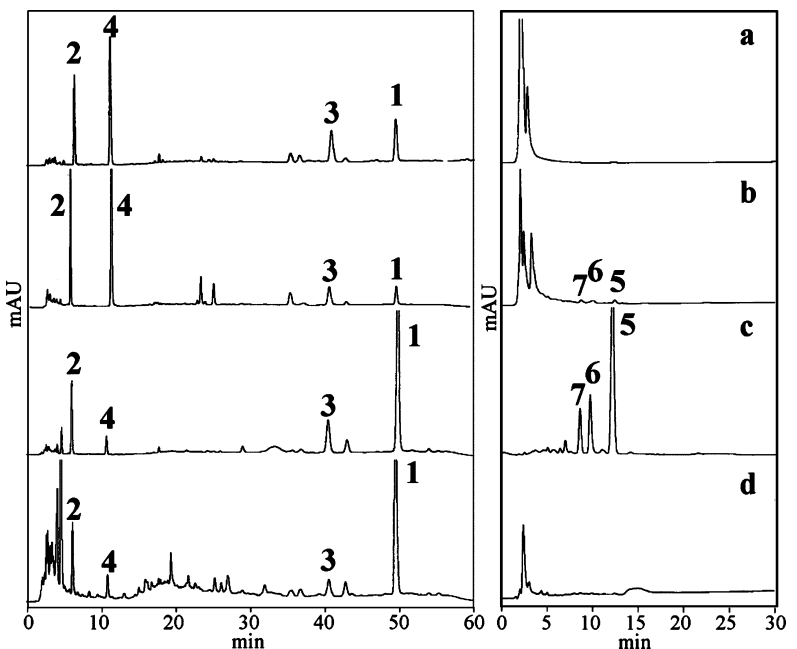

Fig. 4. HPLC Chromatograms of Water or Methanol Solutions of the Phytomedicines containing Salvia Roots

$\mathrm{a}, \mathrm{b}, \mathrm{c}$ and $\mathrm{d}$ indicate phytomedicines of $\mathrm{X}_{\mathrm{A}}, \mathrm{F}_{\mathrm{E}}$ (20030608), $\mathrm{T}_{\mathrm{H}}$ and $\mathrm{K}_{\mathrm{I}}$ (ACCA) listed in Table 3, respectively. For $1-7$, see the legend of Fig. 2.

Table 3. Quantitation of 7 Marker Components in the Phytomedicines Containing Salvia Root Using HPLC

\begin{tabular}{|c|c|c|c|c|c|c|c|c|c|c|}
\hline \multirow{2}{*}{$\begin{array}{c}\text { Preparation } \\
\text { samples (batch No.) }\end{array}$} & \multirow{2}{*}{$\begin{array}{l}\text { Dosage forms } \\
\text { (market) }\end{array}$} & \multirow{2}{*}{ Declaration } & \multicolumn{7}{|c|}{ Content (mg/g or ml) } & \multirow{2}{*}{$\begin{array}{l}\text { Max. recommended } \\
\text { daily dose }\end{array}$} \\
\hline & & & LAB & DSS & RA & PA & $\mathrm{TaII}_{\mathrm{A}}$ & TaI & $\mathrm{CT}$ & \\
\hline$X_{\Delta}$ & Injection (China) & $\mathrm{PA} \geq 0.17 \mathrm{mg} / \mathrm{ml}$ & 0.86 & 1.06 & 0.51 & 0.36 & n.d. & n.d. & n.d. & $20 \mathrm{ml}$ \\
\hline $\mathrm{X}_{\mathrm{B}}$ & Injection (China) & $\mathrm{PA} \geq 0.17 \mathrm{mg} / \mathrm{ml}$ & 0.69 & 2.07 & 0.21 & 0.27 & n.d. & n.d. & n.d. & $20 \mathrm{ml}$ \\
\hline$X_{C}(0200916)$ & Injection (China) & $\mathrm{PA} \geq 0.17 \mathrm{mg} / \mathrm{ml}$ & 0.35 & 1.56 & 0.23 & 0.51 & n.d. & n.d. & n.d. & $20 \mathrm{ml}$ \\
\hline$X_{C}(030409)$ & Injection (China) & $\mathrm{PA} \geq 0.17 \mathrm{mg} / \mathrm{ml}$ & 0.81 & 1.49 & 0.28 & 0.23 & n.d. & n.d. & n.d. & $20 \mathrm{ml}$ \\
\hline $\mathrm{X}_{\mathrm{D}}$ & Injection (China) & $\mathrm{PA} \geq 0.17 \mathrm{mg} / \mathrm{ml}$ & 0.63 & 4.03 & 0.60 & 0.69 & n.d. & n.d. & n.d. & $20 \mathrm{ml}$ \\
\hline$F_{E}(20030608)$ & Dripping pill (China) & $\mathrm{DSS} \geq 0.08 \mathrm{mg} /$ pill & 1.65 & 7.57 & 1.16 & 1.76 & Trace & Trace & Trace & $0.81 \mathrm{~g}$ (30 pills) \\
\hline$F_{E}(20031101)$ & Dripping pill (China) & $\mathrm{DSS} \geq 0.08 \mathrm{mg} / \mathrm{pill}$ & 2.77 & 7.44 & 1.38 & 2.09 & 0.03 & 0.03 & 0.03 & $0.81 \mathrm{~g}$ (30 pills) \\
\hline $\mathrm{T}_{\mathrm{F}}$ & Capsule (China) & n.i. & 1.59 & 9.15 & 0.39 & 0.40 & 1.10 & 1.24 & 1.62 & $1.8 \mathrm{~g}$ (6 capsules) \\
\hline $\mathrm{T}_{\mathrm{G}}$ & Capsule (China) & n.i. & 17.1 & 3.67 & 0.78 & 0.16 & 1.25 & 0.33 & 0.80 & $1.8 \mathrm{~g}$ (6 capsules) \\
\hline $\mathrm{T}_{\mathrm{H}}$ & Capsule (China) & n.i. & 16.6 & 3.56 & 2.16 & 0.20 & 3.97 & 0.67 & 0.82 & $1.8 \mathrm{~g}$ ( 6 capsules $)$ \\
\hline $\mathrm{K}_{\mathrm{I}}$ (ACCA) & Granule (Japan) & n.i. & 7.12 & 1.82 & 0.56 & 0.14 & Trace & Trace & Trace & $9.0 \mathrm{~g}$ (3 parcels) \\
\hline $\mathrm{K}_{\mathrm{I}}(\mathrm{ADAA})$ & Granule (Japan) & n.i. & 7.78 & 1.66 & 0.54 & 0.14 & Trace & Trace & Trace & $9.0 \mathrm{~g}$ (3 parcels) \\
\hline $\mathrm{K}_{\mathrm{I}}(\mathrm{AMDA})$ & Granule (Japan) & n.i. & 7.62 & 1.47 & 0.52 & 0.13 & Trace & Trace & Trace & $9.0 \mathrm{~g}$ (3 parcels) \\
\hline $\mathrm{K}_{\mathrm{J}}(\mathrm{EX}-252330)$ & Granule (Japan) & n.i. & 15.5 & 1.71 & 0.88 & 0.12 & Trace & Trace & Trace & $6.0 \mathrm{~g}$ (3 parcels) \\
\hline $\mathrm{K}_{\mathrm{J}}(\mathrm{EX}-402117)$ & Granule (Japan) & n.i. & 20.5 & 1.67 & 1.17 & 0.12 & Trace & Trace & Trace & $6.0 \mathrm{~g}$ (3 parcels) \\
\hline $\mathrm{K}_{\mathrm{K}}(2 \mathrm{~A} 2)$ & Granule (Japan) & n.i. & 4.99 & 1.23 & 0.21 & 0.08 & Trace & Trace & Trace & $9.0 \mathrm{~g}$ (3 parcels) \\
\hline $\mathrm{K}_{\mathrm{K}}(3 \mathrm{~A} 1)$ & Granule (Japan) & n.i. & 4.32 & 1.51 & 0.18 & 0.08 & Trace & Trace & Trace & $9.0 \mathrm{~g}$ (3 parcels) \\
\hline $\mathrm{K}_{\mathrm{K}}(3 \mathrm{~A} 2)$ & Granule (Japan) & n.i. & 6.31 & 1.64 & 0.27 & 0.10 & Trace & Trace & Trace & $9.0 \mathrm{~g}$ (3 parcels) \\
\hline $\mathrm{K}_{\mathrm{L}}(030501)$ & Tablet (Japan) & n.i. & 15.5 & 2.64 & 0.98 & 0.22 & Trace & Trace & Trace & $6.3 \mathrm{~g}$ (18 pieces) \\
\hline $\mathrm{K}_{\mathrm{L}}(030502)$ & Tablet (Japan) & n.i. & 15.3 & 2.37 & 0.93 & 0.17 & Trace & Trace & Trace & $6.3 \mathrm{~g} \mathrm{(18} \mathrm{pieces)}$ \\
\hline $\mathrm{K}_{\mathrm{L}}(030503)$ & Tablet (Japan) & n.i. & 15.8 & 2.01 & 0.84 & 0.12 & Trace & Trace & Trace & $6.3 \mathrm{~g}$ (18 pieces) \\
\hline
\end{tabular}

n.i., not indicated. n.d., not detectable $(\leq 20.4 \mu \mathrm{g} / \mathrm{ml})$. trace $(>0.4 \mu \mathrm{g} / \mathrm{ml}$, and $<$ minimum of the linear range). The formula of $\mathrm{K}$-series of preparations were comprised by Salvia Root (丹参), Dalbergia Heartwood (降香), that of F-series ones comprised by Salvia Root, Notoginseng Root (三七) and borneol (水片), that of T-series ones only comprised by Salvia Root, and that of K-series ones only comprised by Salvia Root, Safflower (紅花), Peony Root (䓎薬), Cnidium Rhizome (川芦)，Saussurea Root (木香) and Cyperus Rhizome (香附子). 


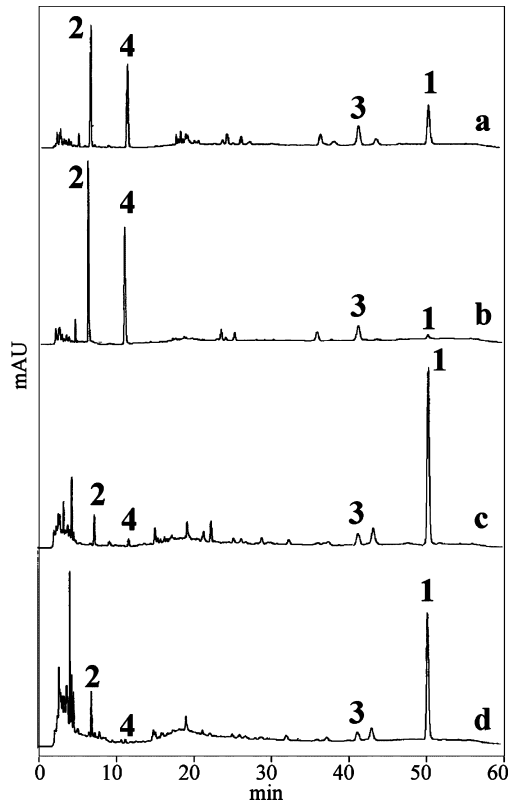

Fig. 5. HPLC Chromatograms for the Stability Trials of the Preparations containing Salvia Root

(a) and (c) are the chromatograms of the injection and granule contaning Salvia Roo at month 0 , respectively. (b) and (d) are those of the samples stored at $40^{\circ} \mathrm{C}$ for six month, respectively. The others are the same as indicated Fig. 2.

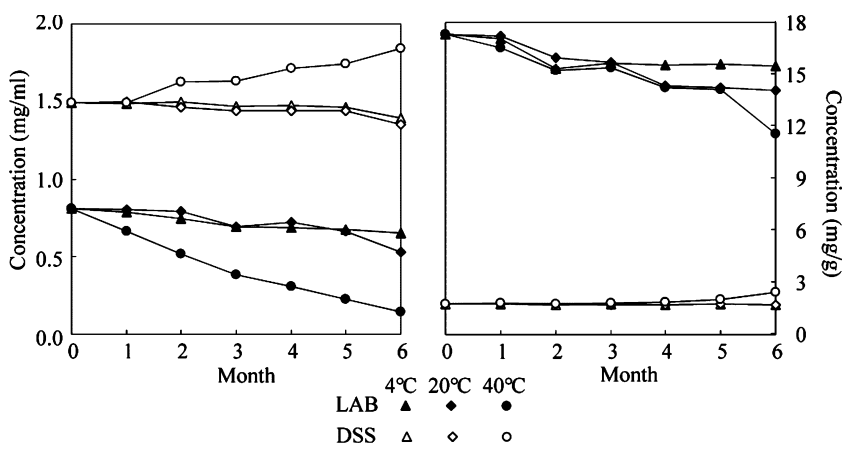

Fig. 6. Decomposition of Lithospermic Acid B and Formation of Danshensu in the Preparations of Salvia Root in Stability Trials

The left indicate the injection sample, with the right being the granule one. All of them are the same as those used in Fig. 5. For stability trials, see Experimental section.

time. At the lower temperature of $4{ }^{\circ} \mathrm{C}$ or $20^{\circ} \mathrm{C}$, the DSS content, both in the granule and in the injection, decreased from about $3 \%$ (the granule) to $10 \%$ (the injection) in comparison with the original level. Thus, LAB showed a temperature independent instability without relation to dosage forms, and the variation of the amount of DSS was not parallel to the instability of LAB. The data were rather different from the instability of the single LAB solution, as shown in Fig. 3, which difference may resulted from the existence of other, yet unknown, constituents present in the preparations. The results from the trials at $40^{\circ} \mathrm{C}$, similar to the accelerated stability tests, suggest that Salvia Root preparations are inappropriate to a long-term storage even if being stored at a normal temperature, and that a solid preparation may be preferable to a liquid one for Salvia Root preparations. Thus, an adequate stabilizing agent or preparations for injection should be developed in the future.

\section{Conclusion}

From the present study, we conclude that the reliable extractive method combined with the efficiency of modern HPLC separation techniques provide a major contribution to the analysis of phenolic caffeic acid derivatives and tanshinones in Salvia Root as well as its phytomedicinal preparations. Owing to a lower stability of LAB and decomposition products of DSS, standardization of phytomedicines containing Salvia Root with respect to these compounds should be preferred.

Our systematically chemical investigation shows that the composition profile of LAB and DSS in the preparations does not seem to be relevant to that in the crude plant material. The additional alterations of active ingredients may be induced by the manufacturing process, and water is a prerequisite for the decomposition of LAB into DSS or other components at higher temperatures. The solid preparations are, therefore, preferable to liquid ones from the standpoint of stability of the active components.

Phytomedicines are complex mixtures of substances, and the crude plant material varies largely in the content of active ingredients. Therefore, the demands of manufacturers can only be met by comprehensive quality control. This control should include the crude plant material, the manufacturing process as well as standardization of the final product. ${ }^{39)}$ With respect to the phytomedicines containing Salvia Root, not only the identity of the plant material and the extraction procedure should be provided, but also the amount of the components present in the preparations by which they may be standardized.

Acknowledgement We are grateful to Iskra Co. Ltd. for providing authentic chemical compounds contained in Salvia Root.

\section{References}

1) Xia Z., Gu J., Ansley D. M., Xia F., Yu J., J. Thorac. Cardiovasc. Surg., 126, 1404-1410 (2003).

2) Wang L., Xiong Z. Y., Wang G., Chin. J. Integrated Trad. Chin. West. Med., 24, 500-504 (2004).

3) Min L. Q., Dang L. Y., Ma W. Y., Chin. J. Integrated Trad. Chin. West. Med., 22, 353-355 (2002).

4) Liu Q., Lu Z., J. Tongji Med. Univ., 19, 40-41 (1999).

5) Cao C. M., Xia Q., Zhang X., Xu W. H., Jiang H. D., Chen J. Z., Life Sci., 72, 2451-2463 (2003).

6) Lo C. J., Lin J. G., Kuo J. S., Chiang S. Y., Chen S. C., Liao E. T., Hsieh C. L., Am. J. Chin. Med., 31, 191-200 (2003).

7) Kang D. G., Yun Y. G., Ryoo J. H., Lee H. S., Am. J. Chin. Med., 30, 87-93 (2002)

8) Zhu Y. Z., Huang S. H., Tan B. K., Sun J., Whiteman M., Zhu Y. C., Nat. Prod. Rep., 21, 478- 489 (2004).

9) Zhao B. L., Jiang W., Zhao Y., Hou J. W., Xin W. J., Biochem. Mol. Biol. Int., 38, 1171-1182 (1996).

10) Masimu R., Tanaka K., Tezuka Y., Gong Z. N., Li J. X., Basnet P., Namba T., Kadota S., Chem. Pharm. Bull., 46, 500-504 (1998).

11) Gu M., Zhang G., Su Z., Ouyang F., J. Chromatogr. A, 1041, 239-243 (2004).

12) Zhang H., Yu C., Jia J. Y., Leung S. W., Siow Y. L., Man R. Y., Zhu D. Y., Acta Pharmacol. Sin., 23, 1163-1168 (2002).

13) Chen C. P., Yokozawa T., Chung H. Y., Exp. Toxicol. Pathol., 51, 5963 (1999)

14) Liu G. T., Zhang T. M., Wang B. E., Wang Y. W., Biochem. Pharmacol., 43, 147-152 (1992).

15) Yagi A., Fujimoto K., Tanonaka K., Hirai K., Takeo S., Planta Med., 55, 51-54 (1989).

16) Soung D. Y., Rhee S. H., Kim J. S., Lee J. Y., Yang H. S., Choi J. S., Yokozawa T., Han Y. N., Chung H. Y., J. Pharm. Pharmacol., 55, $1427-1432$ (2003). 
17) Kang D. G., Oh H., Chung H. T., Lee H. S., Phytother. Res., 17, $917-$ 920 (2003).

18) Lay I. S., Chiu J. H., Shiao M. S., Lui W. Y., Wu C. W., Planta Med., 69, 26-32 (2003)

19) Lay I. S., Hsieh C. C., Chiu J. H., Shiao M. S., Lui W. Y., Wu C. W., J. Surg. Res., 115, 279-285 (2003).

20) Zhang Y., Akao T., Nakamura N., Duan C. L., Hattori M., Yang X. W., Liu J. X., Planta Med., 70, 138-142 (2004).

21) Li C. Z., Yang S. C., Zhao F. D., Yang Y. Q., Yang C. X., Zhang D. C., J. Integrated Traditional Chinese and Western Med., 3, 297-299 (1983).

22) Bors W., Michel C., Stettmaier K., Lu Y., Foo L. Y., Biol. Res., 37, 301-311 (2004).

23) Fan Z., Nakayama K., Sawanobori T., Hiraoka M, Pflugers Arch., 421, 409-415 (1992).

24) Wu T. W., Zeng L. H., Fung K. P., Wu J., Pang H., Grey A. A., Weisel R. D., Wang J. Y., Biochem. Pharmacol., 46, 2327-2332 (1993).

25) Lam B. Y., Lo A. C., Sun X., Luo H. W., Chung S. K., Sucher N. J., Phytomedicine, 10, 286-291 (2003).

26) Ren Y., Houghton P. J., Hider R. C., Howes M. J., Planta Med., 70, 201-204 (2004).

27) The State Pharmacopoeia Commission of China, "Pharmacopoeia of the People's Republic of China," Vol. 1, Chemical Industry Press, Peking, China, 2000, pp. 57-58.

28) The State Pharmacopoeia Commission of China, "Pharmacopoeia of the People's Republic of China," Vol. 1, Chemical Industry Press,
Peking, China, 2000, pp. 518-519.

29) The State Pharmacopoeia Commission of China, "Pharmacopoeia of the People's Republic of China," Vol. 1, Chemical Industry Press, Peking, China, 2000, pp. 519-520.

30) The State Pharmacopoeia Commission of Ministry of Public Health, P. R. China, "Specification of Traditional Patent Medicines Promulgated by Ministry of Public Health," Vol. 17, P. R. China, People's Medical Publishing House, Peking, 1998, pp. 200.

31) Takahashi K., Ouyang X, Ueshima E., Komatsu K., Hattori M., Takahashi K., Kurowaka N., Higasi J., Abtracts of Papers, The 122th Anunal Meeting of Pharmaceutical Society of Japan, Osaka, on April 2003, p. 192.

32) Ueng Y. F., Kuo Y. H., Peng H. C., Chen T. L., Jan W. C., Xenobiotica, 33, 603-613 (2003).

33) Dai Z., Qian Z. Z., Chin. Trad. Patent Med., 18, 10-11 (1996).

34) He H. B., Wang J. M., J. Shanghai Med. Univ., 18, 27-32 (1991).

35) Sun P., He L. Y., Chin. Pharm. J., 32 (Suppl.), 1997, 26-28 (1997).

36) Ye G., Wang C. S., Li Y. Y., Ren H., Guo D. A., J. Chromatogr. Sci., 41, 327-330 (2003).

37) Jin Z. Z., Zhu M., Zhang W. T., Qi Y. F., Chin. Trad. Herb. Drugs, 35, 1174-1177 (2004).

38) Zhao F. Q., Zheng N. X., Sato H., Adachi I., Horikoshi I., Biol. Pharm. Bull., 20, 285-287 (1997).

39) Bauer R., Czygan F., Franz G., Ihrig M., Nahrstedt A., Sprencher E., Z. Phytother, 15, 82-91 (1994). 